\title{
O PROBLEMA DA DESIGUALDADE SOCIAL NA TEORIA DA SOCIEDADE DE NIKLAS LUHMANN**
}

\author{
Roberto Dutra Torres Junior
}

\begin{abstract}
A teoria da sociedade de Niklas Luhmann é frequentemente acusada de conservadorismo, visto que negligencia a relevância das estruturas de desigualdade na sociedade moderna. Este artigo propõe uma leitura alternativa dessa teoria, a qual implica uma reconsideração do papel das estruturas de desigualdade para a reprodução dos sistemas sociais. O argumento principal é que as estruturas de desigualdade orientam o modo pelo qual os sistemas sociais selecionam os indivíduos para suas operações. Ao mesmo tempo, é feita uma defesa da tese luhmanniana sobre o primado da diferenciação funcional, pois, enquanto as estruturas de desigualdade podem variar, assumindo formas contingentes, cuja transformação não representa a transformação da sociedade, a diferenciação funcional, ao contrário, representa a própria identidade da sociedade, permanecendo como uma dimensão invariável e necessária nos horizontes de sentido da modernidade.

Palavras-chave: Teoria da sociedade. Diferenciação funcional. Desigualdade social. Contingência. Modernidade.
\end{abstract}

\section{INTRODUÇÃO}

O esforço de reatar os vínculos entre as análises sociológicas sobre a desigualdade e a teoria social ocupa grande espaço na sociologia alemã e é fortemente marcado pela discussão que busca relacionar desigualdade social e diferenciação funcional (Schwinn, 1998, 2000, 2004, 2007; Schimank, 1998, 2008; Stichweh, 2009, 2010; Weiß, 2004; Nassehi, 2004a, 2004b; Kieserling, 2008; Münch, 2010). O debate gira em torno do significado e do lugar desses dois conceitos numa teoria geral da sociedade. Apesar de ser um debate que congrega weberianos, luhmannianos e bourdiesianos, o foco principal tem sido a tese de Luhmann segundo a qual a

\footnotetext{
* Doutor em Sociologia. Professor Associado do Laboratório de Gestão e Políticas Públicas (LGPP), Universidade Estadual do Norte Fluminense Darcy Ribeiro (UENF).

Av. Alberto Lamego, 2000. Parque Califórnia. Cep: 28013600. Campos dos Goytacazes - Rio de Janeiro - Brasil.robertodtj@yahoo.com.br

** Este artigo resume os argumentos apresentados nos capítulos um e dois de minha tese de doutorado, defendida em dezembro de 2012 no Institut für Sozialswissenschaften da Humboldt Universität zu Berlin: Funktionale Differenzierung, soziale Ungleichheit und Exklusion: eine theoretische Interpretation und eine Analyse des Falls Brasilien. A tese foi publicada como livro: Funktionale Differenzierung, soziale Ungleichheit und Exklusion. Konstanz/Münch: UVK, 2013.
}

diferenciação funcional teria substituído a diferenciação estratificada como forma primária de diferenciação social. Nesse sentido, essa tese é frequentemente interpretada como se ela implicasse a impossibilidade de um conceito de desigualdade social estruturada (Schwinn, 2007). Neste texto, busco formular uma leitura alternativa da tese do primado da diferenciação funcional. Esta leitura implica uma reconsideração do papel das estruturas de desigualdade para a reprodução dos sistemas sociais e desdobra-se em duas teses sobre a teoria da sociedade de Luhmann. A primeira (I) é a de que o primado da diferenciação funcional deve ser entendido como o fato de que essa forma de diferenciação sistêmica tornou-se "autoevidente” (Selbstverständlichung). Essa interpretação baseia-se na constatação, ressaltada por alguns luhmannianos como Armin Nassehi, de que o primado da diferenciação funcional refere-se à "dimensão objetiva" (Sachdimension) do sentido social: ele define o horizonte e a alcançabilidade de temas e problemas que se diferenciam junto com os sistemas funcionais. Assim, é preciso analisar as relações entre essa "dimensão objetiva" e as demais dimensões 
do sentido social: a dimensão social (Sozialdimension) e a dimensão temporal (Zeitdimension). Essa interpretação da tese do primado não implica nem a dissolução do conceito de desigualdade social estruturada nem a sua irrelevância para a questão da ordem social.

A segunda tese (II) é a de que o primado da diferenciação funcional implica a possibilidade de que estruturas de desigualdade sejam percebidas como contingentes (como possíveis de outro modo) em sua contribuição para a ordem social. Por desigualdade social deve-se entender a distribuição desigual de chances de participação comunicativas por meio da construção e da atribuição de endereços sociais (dimensão social). A contingência da desigualdade social decorre de que a construção e a atribuição de endereços sociais é sempre uma operação interna dos sistemas sociais, rompendo-se, assim, o imperativo de que as desigualdades produzidas em um sistema sejam tomadas como necessárias por outro sistema. ${ }^{1}$

\section{O PRIMADO DA DIFERENCIAÇÃO FUNCIONAL}

A tese do primado da diferenciação funcional é frequentemente compreendida como * se ela implicasse a dissolução do conceito de

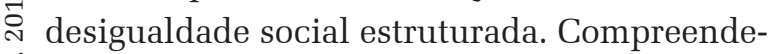
Фं se o conceito de primado como se as "formas ¿̊ં secundárias de diferenciação” (diferenciação - segmentar, estratificação e diferenciação entre centro e periferia) tivessem de ser deduzidas da forma primária de diferenciação. Afirma-se, i portanto, que a tese do primado e a existência a dessas "formas secundárias" de diferenciação స como dimensões estruturais de tipo próprio negam-se mutuamente. ${ }^{2}$ No que se refere à ${ }^{1} \mathrm{O}$ fato de romper-se esse imperativo, definidor de sociedades primariamente diferenciadas em estamentos hierár-

quicos, não significa que não possa ocorrer a transmissão de desigualdades entre sistemas sociais, como é o caso do fenômeno da cumulação de exclusões.

${ }^{2}$ Um das mais importantes contribuições para a análise da relação entre a diferenciação centro-periferia e a diferenciação funcional é a do brasileiro Marcelo Neves (2006). estratificação social, diz-se que a tese do primado é incompatível com uma compreensão adequada da desigualdade social estruturada (Schwinn, 2007, p. 15); que, em decorrência dela, seria necessário postular “[...] o desmonte das formas verticais e hierarquizadas de desigualdade social nas sociedades do bem-estar social” (Haller, 1986, p. 180).

Essas críticas não são injustificadas, pois Luhmann não define de modo claro o conceito de primado e, consequentemente, a relação entre as formas primárias e "secundárias" de diferenciação:

Deve-se falar em primado de uma forma de diferenciação [...] quando se pode identificar que esta regula as possibilidades de emprego das outras. Neste sentido, as sociedades de nobreza (Adelsgesellschaften) são sociedades primariamente diferenciadas por estratificação, mas elas mantêm uma diferenciação segmentar em comunidades domésticas (Haushalte) e famílias, a fim de permitir a endogamia da nobreza assim como de assegurar que as famílias nobres possam se distinguir das famílias não nobres. Na sociedade funcionalmente diferenciada existe estratificação na forma de classes sociais e diferenças entre centro e periferia, mas estes fenômenos são agora produtos colaterais da dinâmica própria dos sistemas funcionais (Luhmann, 1997b, p. 612 tradução nossa).

Parece ser inquestionável que estratificação e diferenciações entre centro e periferia têm a ver com a dinâmica própria dos sistemas funcionais. Assim com não há dúvida de que esses fenômenos, por assim dizer, se alimentam da não transparência mútua entre os subsistemas funcionais. O que está em questão é como definir conceitualmente a relação entre essas diferentes formas de desigualdade social e a diferenciação funcional. Mas a afirmação de que elas são produtos colaterais da dinâmica própria dos sistemas funcionais certamente não contribui para a busca de precisão conceitual, pois ela traz exigências ao conceito de primado que ele não pode atender. Seguindo essa linha de interpretação (que chamarei de "versão ortodoxa da tese do primado funcional”), André Kieserling ${ }^{3}$ defende a tese de que

${ }^{3}$ Nesse sentido, Kieserling é mais preciso do que Luhmann, 
diferenciação funcional implica a neutralização dos condicionantes de origem social sobre as decisões internas dos subsistemas (Kieserling, 2008, p. 16, rodapé 32). Segundo ele, a origem social permanece relevante no que se refere ao recrutamento ou seleção de pessoas para participar dos sistemas funcionais (inclusão), mas não no que tange às decisões internas e ao comportamento que os indivíduos desempenham nos papéis sociais que assumem quando incluídos nesses sistemas. A neutralização de desigualdades externas é entendida como condição necessária para a autonomia operacional dos diferentes sistemas funcionais em particular e para o primado da diferenciação funcional como um todo (Kieserling, 2008, p. 17). Gostaria de designar essa interpretação da teoria luhmanniana da sociedade como a versão ortodoxa da tese do primado funcional.

Se a tese do primado estiver fundamentada nessa neutralização, ela está refutada desde o começo. A sociologia da desigualdade social já demonstrou, de modo suficiente (Schwinn, 2007), que a grande maioria dos sistemas funcionais, mesmo possuindo uma lógica própria, não neutraliza os condicionantes de origem e, além disso, que o acesso às posições, em um sistema funcional, nas quais decisões internas ao sistema são tomadas, não pode ser deduzido da própria diferenciação funcional. Foi, sobretudo, Thomas Schwinn (2007, p. 11) quem questionou a tese do primado a partir dessas constatações da sociologia da desigualdade. A questão agora é averiguar se essa tese, ou seja, se a regulação das formas "secundárias" de diferenciação através da forma primária pode ter outro significado que não seja o da derivação de desigualdades sociais a partir da lógica própria dos sistemas funcionais, o que, por sua vez, pressupõe a neutralização de desigualdades externas.

Minha tese é a de que o primado da diferenciação funcional dispensa tanto a derivação

as possibilidades de emprego de outras formas de diferenciação como critério do primado: neutralizar os efeitos da estratificação nas operações dos sistemas funcionais, restringindo o seu significado à "esfera privada". das desigualdades sociais a partir da diferenciação funcional como a neutralização de desigualdades externas e dos condicionantes de origem no contexto das operações dos sistemas funcionais. Mas só se pode falar em primado quando e somente se houver uma assimetria entre distintas formas de diferenciação. Nesse sentido, sugiro que é possível, a partir dos escritos do próprio Luhmann, redefinir essa assimetria da seguinte forma: a diferenciação funcional tornou-se uma forma de diferenciação social autoevidente (Selbstverständlichung), de modo que os sistemas funcionais podem dispensar qualquer fundamento externo, ao passo que as outras formas de diferenciação, por não serem (mais) autoevidentes, precisam se fundamentar na diferenciação funcional. Isso decorre do fato de a diferenciação funcional significar essencialmente que a diferenciação entre subsistemas sociais passa a se orientar por problemas fundamentais objetivos (dimensão objetiva) (Bommes; Tacke, 2006, p. 42), de modo que a diferença entre os problemas específicos de cada sistema funcional se afirma como um dado necessário (não contingente) da vida social, como se não fosse possível haver sociedade de outro modo. A esse primado funcional-objetivo corresponde o fato de que a construção de "endereços sociais" (dimensão social) e, junto com isso, a distribuição ou atribuição de chances comunicativas passa a ser percebida como contingente, como se fosse possível de outro modo.

O primado da diferenciação funcional refere-se a um horizonte de problemas fundamentais objetivos - assegurar provisão futura em condições presentes de escassez (economia), tomada de decisões coletivamente vinculantes (política), preparação para a vida futura (ensino), assegurar expectativas normativas (direito) - que abarca todas as comunicações possíveis em seu aspecto temático (Nassehi 2004a). O critério para a assimetria, sem a qual não se pode falar em primado, é, portanto, uma fronteira do sentido (Sinngrenze) regulada pela diferenciação funcional, na qual todas as concepções de ordem social encontram seu 
limite e além da qual não se pode imaginar nenhuma possibilidade de ordem. Essa fronteira constitui o limite inalcançável da sociedade como aquele sistema social que abarca todos os outros sistemas sociais. Por isso, a sociedade não pode ser definida como uma entidade, mas somente como um horizonte de todas as comunicações possíveis. Nesse ponto, tomo emprestada a sugestão de Nassehi (2004a, p. 102),

Assim como nenhuma operação monetária é capaz de fugir da lógica econômica, toda fé é sempre uma fé religiosa e toda crítica estética da arte acaba se afirmando como arte. Mas não se pode alcançar a estrutura daquilo que, como o "econômico", o "religioso” e o "artístico”, produz ondas comunicativas. É preciso compreender a sociedade funcionalmente diferenciada como um horizonte inalcançável de comunicações $^{4}$ - se ele fosse alcançável, não seria um horizonte -, no qual, com a ajuda de meios de comunicação simbolicamente generalizados, ${ }^{5}$ emergem relações em que a conectividade entre elementos é altamente provável; essas comunicações se fecham como sistemas funcionais no momento

${ }^{4}$ A comunicação é o componente elementar, a operação específica dos sistemas sociais. Ela consiste na síntese de três seleções: participação (Mitteilung), informação (Information) e compreensão (Verstehen) da diferença entre participação e informação. Deve-se falar em comunicação quando Ego compreende que Alter participou a ele uma informação; essa informação pode, assim, ser atribuída a Alter. A comunicação só acontece se ela for compreendida: quando a informação ("está chovendo") e a intenção que Alter vincula à participação (Alter deseja, por exemplo, fazer com que Ego pegue um guarda-chuva) são compreendidas como seleçôes diferentes. A informação não é algo transmitido na comunicação, mas sim construída na comunicação. Nos

* sistemas sociais, as comunicações são produzidas em uma

- rede recursiva de comunicaçõ̌es, a qual define a unidade i

คิ

๑ ${ }^{5}$ Meios de comunicação simbolicamente generalizados são - estruturas específicas que asseguram possibilidade de su-

œ cesso à comunicação, tornando provável algo inicialmente

- improvável: que a seleção de Alter seja aceita por Ego. O

ถึ sucesso da comunicação é improvável porque Ego pode re-

' cusar a seleção sugerida por Alter (um favor, uma sugestão,

to uma ordem, uma proposta de compra) como premissa para

$\dot{2}$ sua conduta seletiva. Nem todas as comunicações linguis-

i ticamente codificadas precisam de um meio de comunica-

₹ ção simbolicamente generalizado. Em sociedades nas quais

\& toda comunicação é oral, as chances de recusa e aceitação

- de uma comunicação são estruturadas por experiências va-

ลิ lorativas e uma memória social compartilhada, assim como

$\dot{>}$ pela pressão em favor do consenso exercida pela presença

ثิ interativa. Com a difusão da comunicação entre ausentes

- o que torna a aceitação da comunicação improvável -,

isso se torna impossível. A motivação de Ego em aceitar a

స్ seleção de Alter torna-se improvável, e o desenvolvimento

dos meios de comunicação simbolicamente generalizados

é precisamente uma reposta a esse problema da comuni-

ç cação entre ausentes e desconhecidos. Em seu desenvolvi-

mento e diferenciação, os meios de comunicação simboli-

camente generalizados se constituem como constelações

de atribuição e coordenação de ações e vivências aos parti-

3 cipantes da comunicação (Baraldi; Corsi; Esposito, 1997). em que elas se tornam insubstituíveis em relação às funções que desempenham.

Essa definição do conceito da sociedade - que é inseparável do conceito de primado - leva em conta o fato de que a diferenciação funcional tornou-se uma "ordem autossubstitutiva” (Luhmann, 1997b, p. 158), ou seja, uma ordem no interior da qual todas as concepções de mudança estrutural (incluindo toda crítica social possível) se remetem a uma (re)estruturação dos desempenhos funcionais e (ou) do acesso às soluções que os sistemas funcionais ofertam para os problemas fundamentais que eles mesmos produzem e reproduzem. Dito de outro modo: na "ordem autossubstitutiva" da diferenciação funcional, só se concebe mudança estrutural como autossubstituição dos sistemas funcionais, mas não como dissolução destes sistemas. Cito Luhmann (1992, p. 4748, tradução nossa) mais uma vez:

Nesse sentido, é difícil imaginar nossa sociedade sem Estado, sem direito, sem dinheiro, sem pesquisa e sem comunicação de massas. Funções com esse alcance produzem ordens autossubstitutivas. É difícil imaginar uma ordem social sem sistemas funcionais diferenciados, ou seja, encontrar uma alternativa para a diferenciação funcional.

Condição necessária para o surgimento dessa "ordem autossubstitutiva" é a autonomização das dimensões do sentido (dimensão temporal, dimensão social, dimensão objetiva), de modo que, por exemplo, a dimensão temática de toda comunicação (dimensão objetiva) não seja confundida com o fato de cada indivíduo possuir uma perspectiva própria sobre o mundo (dimensão social). Nesse sentido, a autonomização da dimensão objetiva (Sachdimension) desemboca no desacoplamento de diferentes problemas funcionais fundamentais tanto entre si como em relação à dimensão social (Luhmann, 1984, p. 133-134). A especialização e a monopolização funcionais desses problemas fundamentais ocorrem através da formação de sistemas funcionais que se diferenciam de seu entorno (Umwelt), na medida em que desempenham uma função 
própria para a sociedade. Isso implica que todos os outros subsistemas situados no entorno social (innergesellschaftliche Umwelt) sejam percebidos como incompetentes em relação ao desempenho dessa função. Isso ocorre, sobretudo, porque a especialização de funções assegura um alto nível de desempenho no preenchimento de funções sociais. Esse nível de desempenho decorre do aumento da complexidade interna dos sistemas funcionais, ou seja, das relações possíveis entre os elementos e operações que pertencem à rede de comunicações de um sistema funcional. A atualização seletiva dessas relações deve-se ao surgimento de organizações e "especialistas" (Leistungsrollen) que condicionam o desenvolvimento dos programas sistêmicos, ou seja, das estruturas que regulam a redução da complexidade interna e o uso do código sistêmico.

O aumento e a redução de complexidade interna pressupõem que os subsistemas sociais sejam liberados de uma relação estreita com seu entorno, isto é, com os outros sistemas sociais. Os subsistemas conseguem evitar essa relação estreita através de mecanismos que Luhmann (1997b, p. 759 e 776ss) denomina "acoplamentos estruturais". ${ }^{6}$ Trata-se, nesse caso, de uma relação seletiva com as irritações do entorno. Especialização funcional e acoplamentos estruturais permitem que os subsistemas desenvolvam e sejam conduzidos por uma dinâmica própria (Luhmann, 1997b, p. 761 e 768), a qual também se baseia numa temporalidade e em desigualdades próprias. Decisivo aqui é que a influência de desigualdades externas sobre as operações dos sistemas funcionais não pode mais se dar sem mediações; elas são mediadas pelos programas sistêmicos - embora não neutralizadas. Pessoas com alto poder aquisitivo não possuem, diretamente, por conta de sua riqueza, as competências reconhecidas como necessárias para ocupar po-

6 Acoplamento estrutural deve ser entendido, segundo Luhmann, como o conceito que indica o momento de abertura dos sistemas funcionais operativamente fechados. Ele busca observar a seletividade nas relações de dependência entre os subsistemas. Em última instância o esquema diferenciação-integração (Durkheim, Parsons) deve ser substituído pelo binômio autopoiesis-acoplamento estrutural (Luhmann, 1997b, p. 778). sições no sistema científico e para decidir sobre o uso do código da ciência, ou seja, para decidir o que é uma verdade científica e o que não é. $\mathrm{O}$ fato de existir um conjunto de estratégias de classe que permitem a conversão de poder aquisitivo em prestígio científico, assim como mecanismos que permitem que certas classes ou "milieus" sociais monopolizem o acesso a posições de destaque, como as de juiz, professor, empresário, político etc., não contradiz a dinâmica própria dos sistemas funcionais. Isso porque tais estratégias de conversão e monopolização de chances de acesso precisam levar em conta os programas sistêmicos, assim como o nível interno que rege o desempenho das respectivas funções sociais, não podendo ignorá-los.

Mas o desacoplamento dos diferentes problemas fundamentais somente se consolida quando os subsistemas funcionais conseguem diferenciar sua forma de comunicação das outras formas de comunicação através de uma codificação binária de suas operações. Códigos binários como lícito e ilícito, ter e não ter, verdadeiro e falso, governo e oposição, entre outros, são, em primeiro lugar, esquematizações altamente abstratas, diferenciadas entre si e que sustentam a reprodução autopoiética de um sistema funcional, desde que as operações deste sistema orientem-se exclusivamente pela diferença binária do código. Trata-se da projeção de uma diferença entre valores dicotômicos a partir da qual cada operação, cada valoração, é percebida como contingente em relação à possibilidade de uma operação com o valor oposto. Tais códigos “[...] vinculam cada operação a uma diferença de dois valores - o próprio código - e garantem, com isso, que uma comunicação marcada pelo valor oposto se dê a partir da comunicação presente." (Luhmann, 1997b, p. 749). Códigos binários são "formas de dois lados" que, exatamente pelo fato de, sem a mediação de qualquer outra instância, poderem se diferenciar uma das outras como forma, facilitam, em seu contexto de aplicação, a passagem de um lado da forma ao outro, de um valor para o "contravalor". 
Essa extrema redução de possibilidades a somente dois valores permite que o respectivo sistema só considere como informação as seleções feitas a partir de seu código, ou seja, seleções que já pertencem às operações básicas do sistema. A seletividade do código exclui a possibilidade de que informações sejam importadas do entorno. Além disso, os códigos são também "abstrações condicionais" com aplicação universal. Sempre quando se tratar de ganho de conhecimento na ciência (seja na China ou no Paraguai), é incontornável usar o código verdadeiro ou falso. A autopoieses de um sistema funcional corresponde ao fato de que seu código se mantém constante e capaz de permitir a reprodução permanente de uma forma de comunicação que pertence somente a esse sistema funcional. Um sistema social é sempre o modo como uma forma de comunicação se diferencia de outras formas comunicativas, erigindo, assim, uma fronteira que o destinge do seu entorno. O que o código, na verdade, faz é criar uma relação circular entre seus valores positivos e negativos, de modo que o valor de conexão de suas operações seja resultado direto da diferença entre os dois valores. Com isso, produz-se um contexto de contingência específico do código, no qual as operações são sempre vistas como possíveis de outro modo (contingentes) (Luhmann, 1997b, p. 750): cada స్․ operação é observada à luz da possibilidade de Ф் seu correlato negativo. Isso permite que o código seja reproduzido em todas as operações do - sistema, seja através da alocação do valor posi\& tingente pelo sistema funcional: "Somente a diస ferença pode dar estabilidade a seus dois lados, e isso porque ela está vinculada a um contexto funcional, porque ela se diferencia junto com este contexto e parece ser necessária para ele” (Luhmann, 1988, p. 209).

O código precisa se reproduzir como uma referência invariável e necessária do sistema (Luhmann, 1997b, p. 771, 1987, p. 184).
Caso contrário, o sistema deixaria de existir. Mas, nesse caso, não se trata de necessidade no sentido de um "dado natural", cujos fundamentos estão, como na concepção de mundo da Idade Média, "fora do tempo", mas sim de uma necessidade que podemos chamar de necessidade temporalizada. Com isso, refiro-me ao fato de que a unidade da diferença - que constitui a forma de um código binário e que é usada e reproduzida em todas as suas operações - não é indicada como unidade nas operações que por ela se orientam. Se a diferença do código aparecesse como unidade no nível das operações sistêmicas, essas operações não seriam possíveis, pois a unidade da diferença representa ou um paradoxo ou uma tautologia que, quando identificada como tal, bloqueia qualquer operação que por ela se oriente. Dito de outro modo: as operações que usam o código binário não podem empregá-lo sobre si mesmas. Em todos os subsistemas cujas operações são codificadas de modo binário surge esse problema. O sistema do direito, que se diferencia do entorno por meio da diferença entre lícito e ilícito, se encontraria em uma situação paradoxal ou tautológica se, em suas operações, alguém perguntasse: "Com que direito o sistema estabelece quem tem direito e quem não tem?”. Através desse autoemprego, a unidade da diferença que constitui o código, seja como um paradoxo (ninguém tem o direito de decidir sobre o direito alheio), seja como uma tautologia (direito é direito), funcionaria como um sabotagem insuportável para as operações sistêmicas. A autorreferência circular do código precisa, por meio de uma referência externa como a semântica da vontade popular e da constituição, que acoplam o direito à política, ser interrompida no tempo, de modo a evitar o curto-circuito no processo de produção de sentido. Somente quando as operações sistêmicas tomam o código como diferença entre valores que se contradizem, e não como unidade da diferença, é que elas podem se orientar pelo código.

Com isso se consegue o desdobramento da autorreferência, ou seja, evitar que ela seja, sem mediações 
e de modo compacto, vista como uma unidade (embora essa autorreferência jogue um jogo, por assim dizer, dialético, já que cada valor ganha sua identidade em relação a um 'contravalor" (Luhmann, 1986, p. 77, tradução nossa).

A sociedade e seus subsistemas funcionais são reproduzidos, desdobrados e tornados invisíveis como unidade, no decorrer das operações sistêmicas. Eles existem, como unidade, somente no plano da latência operativa, no plano da autofundamentação de esquemas de valoração diferenciados entre si, ou seja, como "ponto cego" da forma primária da diferenciação. Nas palavras de Luhmann (1997b, p. 369, tradução nossa):

O código concede a si mesmo, por assim dizer, a permissão necessária para operar, sem que para isso tenha de recorrer a valores superiores. Sua autofundamentação não é tematizada, ela permanece latente. Com isso, ela se livra do risco envolvido em toda performance comunicativa (Mitteilung): o risco de receber um sim ou um não. Exatamente nesse sentido é que os lados positivos e negativos do código são ‘valores'[...] E o código pode, assim, afirmar sua autonomia e evitar que seu paradoxo fique visível, e tudo isso com alta plausibilidade. Pois em que alguém poderia se apoiar para questionar o direito de se estabelecer a diferença entre licitude e ilicitude!

O primado da diferenciação funcional se mostra nessa capacidade de autovalidação das fronteiras sistêmicas, a qual desonera os sistemas sociais de terem de fundamentar seus respectivos códigos binários. Na medida em que esses códigos tornam seus paradoxos invisíveis, eles aparecem aos indivíduos, apesar da diferença de perspectivas (dimensão social), como algo "autoevidente". Por isso, a variedade e mesmo as divergências de perspectivas, interesses e pretensões na dimensão social tendem a reproduzir esse caráter autoevidente dos códigos binários, assim como a autoevidência da diferenciação (funcional) entre eles (Sachdimension):

A disjunção entre lícito e ilícito - como também outros esquematismos binários relevantes para a sociedade, como a lógica de dois valores ou a diferença entre propriedade e não propriedade - é, na estrutura social, de tal modo assegurada, para além de contextos específicos, que nenhum interesse contra a própria disjunção consegue se formar nem tornar-se compreensível, mas somente o interesse na licitude, na verdade científica, na propriedade (Luhmann, 1981, p. 228, tradução nossa).

A diferenciação entre sistemas funcionais, códigos valorativos e problemas fundamentais generaliza-se em tal medida, que sua existência se desacopla de qualquer estruturação específica da dimensão social, assim como de qualquer programa sistêmico específico que regula a alocação dos valores sistêmicos em determinadas regiões da sociedade global. A ordem sistêmica orientada pela diferenciação funcional torna-se "uma não contingência fundada no próprio fato de essa ordem existir" (Luhmann, 1984, p. 465). O primado da diferenciação funcional significa que, na sociedade (mundial) moderna, existem possibilidades de comunicação que ultrapassam as fronteiras de estruturas de desigualdade social, assim como as fronteiras criadas por diferenciações segmentares (como os estados nacionais), mas não as fronteiras da própria diferenciação funcional.

Resumindo: o primado da diferenciação funcional significa que essa forma de diferenciação tornou-se autoevidente, de modo que a diferença entre subsistemas funcionais é percebida como uma fronteira de toda ordem imaginável, que, desse modo, regula o emprego das demais formas de diferenciação funcional. Essa "capacidade de regulação" não é, portanto, definida como uma direção dedutiva - como se as formas "secundárias" de diferenciação fossem derivadas da forma primária -, mas como uma fronteira da construção de sentido social: a forma primária de diferenciação ultrapassa as fronteiras das outras formas "não primárias”, sem poder ser ultrapassada por nenhuma delas. Precisamente por isso, deve se definir diferenciação funcional como o horizonte de todas as comunicações possíveis e a unidade da sociedade como a unidade de sua forma primária de diferenciação sistêmica. 


\section{A CONTINGÊNCIA DA DESIGUAL- DADE SOCIAL}

Em sociedades primariamente diferenciadas por estamentos ou castas, mesmo existindo esferas sociais em processo de diferenciação, como religião e política, a existência de uma diferença unitária e hierárquica entre "base" e "topo" era tida como um princípio de diferenciação autoevidente e necessário. O primado da estratificação se expressa no fato de que, mesmo nas esferas sociais em vias de se diferenciar, a ordem social era sempre percebida como dependendo de uma sobredeterminação através de uma diferenciação hierárquica transcontextual. Sem uma respectiva ordem sistêmica hierárquica concreta, segundo a qual o sistema do "topo", por meio de uma legitimação moral e religiosa, domina os estamentos inferiores, a ordem social seria impensável em qualquer contexto:

Quero falar de estratificação somente quando a sociedade é representada como uma ordem hierárquica e quando a ordem tenha se tornado impensável sem essa hierarquia (Luhmann, 1997b. p. 679) E o primado da estratificação só existe quando outras formas de diferenciação (sobretudo a diferenciação segmentar de famílias e comunidades domésticas) se orientam pela estratificação (Luhmann, 1997b, p. 685-686, tradução nossa).

Consequentemente, a transição para o primado da diferenciação funcional só é possível quando a ordem social pode ser produzida mesmo quando as fronteiras de estruturas de estratificação concretas são ultrapassadas.

E isso acontece exatamente com o desenvolvimento (diferenciação) dos códigos binários e seus respectivos subsistemas sociais: através da diferenciação de dicotomias específicas entre "sim" e "não" (ter e não ter, governo e oposição, lícito e ilícito, doente e saudável etc.), os sistemas funcionais podem observar estruturas de desigualdade como sendo contingentes, como sendo mutáveis, sem que isso represente uma "catástrofe evolutiva" para esses sistemas e para a sociedade como um todo. Deve-se falar em primado da diferenciação funcional quando outras formas de diferenciação (sobretudo a estratificação social) não podem mais ser justificadas de modo autoevidente (exoneradas de justificação), carecendo de legitimação perante os códigos binários dos sistemas funcionais, ou seja, quando a autoevidência da diferenciação funcional substitui a autoevidência da estratificação social:

Com a transição da estratificação para a diferencia-
ção funcional, muda-se a forma de diferenciação da
sociedade, mas isso não significa, de modo algum,
a eliminação da estratificação social [...]. Mas houve
uma mudança fundamental: agora a estratificação
não representa mais a ordem visível da sociedade,
não mais aquela ordem sem a qual nenhuma outra
seria possível. Por isso, a estratificação perde sua le-
gitimação por falta de alternativas e, desde o século
dezoito, é confrontada com o postulado da igualda-
de entre todos os seres humanos, segundo a qual as
desigualdades são identificadas e expostas à neces-
sidade de uma justificação funcional. No plano se-
mântico, essa mudança fundamental fica registrada
na transição do conceito de estamento para o con-
ceito de classe social, o qual aponta mais claramen-
te a pura arbitrariedade da estratificação (Luhmann,
1997b, p. 772-773, tradução nossa).

Embora o primado da diferenciação funcional não elimine a estratificação, ele permite, pelo menos, que a ordem social não seja vinculada a uma estrutura de desigualdade social tida como a única possível. Nesse sentido, ele é o pressuposto para a que desigualdade social seja criticada socialmente. Isso contradiz a tese comum de que a especificidade da sociedade moderna reside na "ascensão da burguesia” (Luhmann, 1980, p. 7). O que define a especificidade da sociedade moderna com relação à estratificação social não é o surgimento nem a decadência de nenhuma classe social específica, mas o fato de que qualquer estrutura de estratificação social pode ser observada como contingente.

A contingência da desigualdade social faz-se presente também no nível das trajetórias individuais, as quais, na sociedade moderna, são constituídas por um "futuro em aberto." 
Por causa da diferenciação mais intensa entre os contextos de socialização e os contextos de inclusão (Luhmann, 1989, p. 171 e 220), a posição de origem traz, no máximo, vantagens socializatórias, cujo significado, para os destinos individuais, passa a depender de eventos contingentes, principalmente do encadeamento de decisões em organizações. A mera pertença a uma "família nobre" não pode substituir as competências e recursos relevantes para os sistemas funcionais (Frie, 2005). "Nascimento, socialização doméstica e situação de classe não são mais suficientes para construir expectativas que orientem uma trajetória de vida normal” (Luhmann, 1989, p. 232). Por isso, a origem social só é recursiva quando ela permite aos indivíduos que se preparem para disputar e ocupar posições que somente se tornam acessíveis com a sequência seletiva de eventos na trajetória de vida. Trata-se de um controle dinâmico e temporalizado (condicionado por eventos contingentes) de chances de carreira, cujo êxito depende da preparação para lidar com a contingência dos eventos sociais (Luhmann, 1997b, p. 742).

O fato de a estratificação social não ser mais a forma primária de diferenciação implica também que as estruturas de desigualdade social são obrigadas a se fundamentar e a se legitimar pela diferenciação funcional. Essas estruturas de desigualdade, precisamente quando se trata de desigualdades externas que influenciam as operações dos sistemas funcionais, têm de ser observadas, reconstruídas e descritas como se fossem internas ao sistema. Tomemos o exemplo bourdieusiano da "distinção pelo bom gosto" (Bourdieu, 1982): as formas de classificação (rude e fino, entre outras) que, através da atribuição de "bom gosto", vinculam desigualdades do sistema artístico com as desigualdades das condições externas (não artísticas) necessárias para incorporar esse "bom gosto", precisam se fundamentar no próprio sistema artístico e em seus critérios, e é exatamente por conta disso que as vantagens (externas) ligadas à origem - sobretudo o afas- tamento da urgência econômica - precisam ser tornadas invisíveis. Essa assimetria, que é constitutiva do conceito de primado, fica evidente quando se constata que é impossível uma inversão do argumento: as operações dos sistemas funcionais não podem ser fundamentadas em desigualdades externas.

Mas o primado da diferenciação funcional não significa que essa forma de diferenciação seja capaz de produzir todos os mecanismos necessários para a reprodução dinâmica da sociedade moderna. Ao contrário: visto que a diferenciação entre subsistemas é deslocada para a dimensão objetiva, aparece o problema da "seleção de pessoas" como uma questão especial que a construção da ordem social precisa enfrentar e que não pode ser resolvido pela diferenciação funcional. Com a dissolução do primado da estratificação, também se dissolve o essencialismo pré-moderno que regulava a seleção social de pessoas por meio da referência direta ao seu pertencimento estamental. No lugar desse essencialismo, aparece, no século dezenove, o conceito de população. Uma população consiste de uma variedade de indivíduos (Luhmann, 1997a, p. 25), definidos precisamente por sua indeterminação, pela inexistência de tipificações rígidas, pela necessidade de educação e pelo desenvolvimento de pretensões próprias. Essa variedade de indivíduos, formatáveis pela educação e capazes de desenvolver suas próprias aspirações, é, segundo Luhmann, um correlato direto da diferenciação funcional, pois um indivíduo só pode ser relevante para a esse tipo de sociedade à medida que é capaz de: a) assegurar sua identidade, mesmo participando de situações sociais muito distintas e sendo exposto a exigências comportamentais também diversas; e b) ao perseguir suas aspirações e seus interesses, tomar parte nos diferentes públicos dos sistemas funcionais e, com suas demandas por funções sociais, contribuir para a reprodução dos sistemas funcionais.

Trata-se aqui de uma relação entre a auto-organização dos sistemas funcionais e 
a microdiversidade de seus respectivos públicos. Cada um desses públicos representa, no plano da microdiversidade, um excedente de possibilidades operativas que os sistemas funcionais precisam constantemente domar para que haja ordem social no nível de sua auto-organização. Tudo indica que os mecanismos que permitem reduzir esse excedente de possibilidades operativas precisam ir além da individualização das identidades pessoais. $\mathrm{Na}$ verdade, uma vez que essa individualização consiste em neutralizar diferenças de classe e origem social, é de se esperar que ela contribua para formar o excedente de possibilidades comunicativas, e não para reduzi-lo. A redução dessas possibilidades só é possível quando os sistemas funcionais aceitam assimetrias e desigualdades capazes de estruturar a construção de "endereços sociais" na dimensão social.

A contribuição das assimetrias e desigualdades da dimensão social para a produção e a reprodução da ordem social pode ser observada mais precisamente quando levamos em conta a diferença entre código e programa. Embora o código binário seja constitutivo para a identidade do sistema funcional, ele não carrega, em si mesmo, nenhum critério de seleção que oriente a atribuição de seus valores negativos e positivos. Por isso, o código sozinho ¥ não é capaz de produzir nenhuma operação do సे sistema. Para isso, são necessários programas, Фึ ou seja, premissas de decisão que definam as Condições sob as quais a atribuição dos valores ¿̊ sistêmicos é "correta". Trata-se da reintrodu¿ o sistema só oriente suas operações pelos vaస lores positivo e negativo de seu código - caso

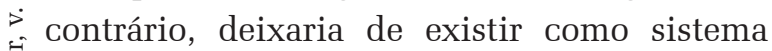
funcional -, ele precisa aceitar um terceiro valor no nível de seus programas, pois esse valor adicional é que permite a realização das operações sistêmicas. Luhmann enfatiza que tais programas são específicos de cada código e de cada sistema funcional: a alocação dos valores de diferentes códigos não pode se dar por meio de um denominador comum. Programas de investimento e de consumo na economia não são capazes de orientar a atribuição dos valores lítico e ilícito no sistema do direito, pois somente normas jurídicas desempenham este papel. Além disso, os programas, ao contrário dos códigos, são contingentes e variáveis. Nesse sentido, o conceito de programa não serve para uma concepção da desigualdade social que pretenda explicar o acesso aos valores dos diferentes sistemas funcionais por meio de uma noção unitária de estrutura social.

Mas é possível supor, sendo coerente com o conceito, que os programas sistêmicos se vinculam de dois modos com estruturas de desigualdade social. Em primeiro lugar, os sistemas funcionais precisam que a contingência, no plano dos programas, seja reduzida de tal modo, que a atribuição dos valores de um único e mesmo código não seja, no mesmo contexto e ao mesmo tempo, disputada por vários programas. As possibilidades de programação precisam ser controladas de algum modo, o que tipicamente ocorre por meio de "especialistas" em organizações. No caso desse controle, o "terceiro valor" introduzido no contexto funcional de um código binário serve não apenas para decidir sobre a alocação de valores, mas também sobre as premissas que vão orientá-la. Esse terceiro valor pode ser, por exemplo, o prestígio de um cientista, que o permite transformar suas novas teorias em programa de sua disciplina científica. Em segundo lugar, toda programação sistêmica, a fim de poder determinar as condições de correção dos comportamentos vinculados à atribuição dos valores binários, exige que a dimensão social seja devidamente estruturada. Para que o comportamento de várias pessoas possa ser coordenado segundo as condições de correção para atribuir os valores sistêmicos, é preciso que a dimensão social tenha sua complexidade reduzida por meio da construção de "pontos de atribuição" (endereços sociais). Esses "pontos de atribuição" orientam a seleção de pessoas 
cujo comportamento social condiz com a respectiva programação das operações sistêmicas. A "questão" dos programas é reduzir o excedente de possibilidades operativas que a impossibilidade de se construírem "endereços sociais" - ou seja, de se personalizarem expectativas de comportamento no plano dos códigos sistêmicos - produz na dimensão social.

Para realizar essa redução de possibilidades operativas, os programas se vinculam, de modo constitutivo, a mecanismos de seleção social. Essa vinculação fica evidente quando se leva em conta a importância das construções ou observações sistêmicas sobre seu público. Tais construções ou observações, como mostra Stäheli (2009), reduzem as possibilidades operativas dos sistemas porque criam uma fronteira entre os "endereços sociais" com as competências para participar das operações dos sistemas funcionais e um "lado de fora" que ou é percebido como uma ameaça a ser afastada e excluída das operações sistêmicas, ou como uma população dotada de um potencial de inclusão capaz de, no futuro, permitir a ampliação das fronteiras do público. Precisamente porque tais construções ou observações não são derivadas da forma de diferenciação funcional é que os sistemas funcionais dependem de programas em geral produzidos e reproduzidos em organizações que delimitem as possibilidades de ação e vivência das pessoas, ou seja, que sejam capazes de construir "endereços sociais". Em sua análise sobre a construção do "público financeiro" nos EUA, Stäheli mostra que tais delimitações são objeto de disputa no contexto dos sistemas funcionais. Que competências são indispensáveis para um "especulador vocacionado" é algo que está submetido às contingências da história e das disputas sociais. E, com isso, também a programação do acesso aos valores (ao tipo de propriedade) em jogo no universo financeiro, pois os programas tomam essas competências como critérios de inclusão e de correção das operações sistêmicas. A disputa central gira em torno das possíveis consequências para a estrutura do público financeiro, decorrentes da inclusão de indivíduos que, segundo a atribuição dos estabelecidos, não tomam decisões de compra e venda de ações e demais papéis segundo os próprios cálculos, reflexões e opiniões, mas sim como parte de uma "massa irracional”, imitando o comportamento dos outros especuladores (Stäheli, 2009, p. 267).

Mesmo enfatizando a individualidade pessoal, esses mecanismos de construção seletiva dos públicos dos sistemas funcionais precisam, tanto quanto possível, ignorar as especificidades individuais, pois somente assim a complexidade do entorno humano pode ser estruturada (reduzida) pelos sistemas sociais. Ao contrário da atribuição meramente individualizante de expectativas de comportamento, as atribuições realizadas por esses mecanismos de seleção de pessoas são generalizadas não apenas na dimensão temporal (ou seja, como duração das expectativas individuais de comportamento), mas também na dimensão social. A autonomização da dimensão social significa a produção de uma dimensão do sentido que ressalta a singularidade das perspectivas individuais, mesmo que os temas e objetos da comunicação (dimensão objetiva) sejam idênticos. Quando essa dimensão do sentido tornase autônoma, não é mais possível determinar as possibilidades de comportamento dos indivíduos por meio de uma definição objetiva do ser humano como uma "coisa", ou um ser especial entre outras "coisas" e seres. Isso porque a dimensão social ressalta justamente a particularidade do "horizonte interior do eu" como um problema que precisa ser solucionado com construções de sentido específicas. E esse é o caso das generalizações supraindividuais de expectativas de comportamento que tomam um "outro generalizado" (Schneider, 2011, p. 111) como referência para a atribuição de propriedades compartilhadas no que tange à estrutura das perspectivas individuais, ou seja, para a atribuição de consenso e (ou) dissenso com relação a determinadas expectativas de comportamento. Essa generalização consiste 
exatamente em substituir o enfoque concreto nas especificidades individuais por um enfoque mais abstrato em modelos de individualização. Mesmo assim, ela não alcança o nível estrutural de papéis sociais com expectativas comportamentais formalmente definidas, mas sim o nível da tipificação informal de indivíduos aptos a assumirem esses papéis sociais.

A relação entre a programação e as generalizações sobre o público dos sistemas funcionais acontece, sobretudo, por meio da atribuição de preferências valorativas que tornam os indivíduos "endereços sociais" legítimos das operações sistêmicas. E isso inclui também os valores positivos dos respectivos códigos binários. Tais preferências valorativas funcionam como índice de que os indivíduos fazem um uso adequado dos meios de comunicação simbolicamente generalizados (dinheiro, poder, fé, amor, verdade etc.). Os sistemas sociais podem, por exemplo, atribuir aos indivíduos " [...] a preferência pela obtenção, pela estabilização ou pela ampliação do poder político, pela multiplicação da propriedade (pela obtenção de lucro), ou pelo desenvolvimento de teorias novas e tomadas como verdadeiras. (Schneider, 2011, p. 112). Com isso, os sistemas funcionais passam a dispor de endereços sociais com o potencial de se identificarem com as formas sociais pro¥ duzidas pelo uso dos códigos binários, ou seja, ণ de realizar e, assim, confirmar as assimetrias Фึ constitutivas desses códigos. A construção de “endereços sociais” (e, logo, a delimitação das fronteiras dos públicos sistêmicos) é constituti\& social) do comportamento" (Luhmann, 1984, సิ p. 432, tradução nossa) que estruturam a alocação dos valores sistêmicos, essas estruturas de programa dependem de assimetrias que reduzam as possibilidades de ação e vivência dos indivíduos. Questões de programação são inseparáveis das questões relativas à seleção de pessoas (Luhmann, 2002, p. 397ss), de modo que a influência de desigualdades externas so- bre a distribuição de posições sociais nos sistemas sociais também se estende às decisões sobre a alocação dos valores em jogo nos sistemas funcionais. Vale repetir: os programas não neutralizam essas desigualdades externas, mas sim as transformam em desigualdades internas por meio de processos de atribuição que tornam as influências externas invisíveis. A tese da neutralização (Kieserling), além de carente de qualquer sustentação empírica, desvia o foco de uma questão decisiva na relação entre desigualdades sociais "não funcionais" (externas aos sistemas funcionais) e diferenciação funcional: a questão do grau de autonomia que os programas sistêmicos possuem em relação às desigualdades externas (produzidas por outros sistemas sociais) nos processos internos de distribuição e atribuição de chances comunicativas. Essa autonomia - eis a hipótese de pesquisa decorrente dessas reflexões teóricas pode ser definida como o grau de liberdade dos programas em tratar as desigualdades externas como referências contingentes para orientar as operações de distribuição e atribuição de chances comunicativas. Um alto grau de autonomia significa que essas operações podem selecionar internamente os critérios de discriminação de pessoas, ou seja, que nenhuma seleção externa prévia impõe-se como necessária. Quando, por exemplo, indivíduos se distanciam das necessidades econômicas imediatas, ou seja, quando agir segundo critérios econômicos, torna-se algo contingente, sua posição econômica passa a não ser tão decisiva na forma como eles participam da política, de modo que partidos podem formular programas voltados para esses indivíduos a partir de critérios que, não necessariamente, passem pela satisfação de suas necessidades imediatas.

\section{CONCLUSÃO}

O objetivo deste artigo foi demonstrar que a teoria da sociedade de Niklas Luhmann é plenamente compatível com uma abordagem que res- 
salte a relevância das estruturas de desigualdade para a reprodução social. Para isso, buscou-se precisar a concepção de primado da diferenciação funcional como traço definidor da sociedade moderna. O primado não significa a neutralização da influência de fatores externos aos sistemas funcionais na produção das desigualdades internas a esses sistemas. Essa versão do conceito não se sustenta face aos sólidos achados da sociologia da desigualdade, os quais confirmam a influência de fatores do entorno sobre as chances de participação individual nas operações dos sistemas sociais. O primado da forma funcional de diferenciação sistêmica - como Luhmann enfatiza em várias passagens - refere-se ao fato de que as formas de comunicação mais importantes e abrangentes da sociedade (economia, política, direito, comunicação de massas, ciência etc.), sem as quais a ordem social não é percebida como possível, não se constituem primariamente pela hierarquização ontológica de pessoas, mas sim pela especificação de relações entre distintos problemas funcionais e soluções.

Mas qual o ganho que a tese do primado funcional traz para a análise da desigualdade? O ganho refere-se, sobretudo, à articulação dos pressupostos sociológicos da observação distanciada da desigualdade, tanto como problema social como problema de pesquisa. A questão primordial para uma teoria social da desigualdade precisa ser o que Luhmann chama de "questão autológica", ou seja, a questão das condições de possibilidade da problematização sociológica (como problematização social!) das assimetrias entre as pessoas. Como é possível que a vida social nos permita ver a desigualdade como um problema, ao invés de como um fundamento inquestionável da própria ordem social? A interpretação da teoria da sociedade de Luhmann - como teoria da diferenciação aqui proposta leva em conta que a criticidade e a problematização da desigualdade social a partir de perspectivas sobre a justiça e a igualdade pressupõem uma ordem social compatível com a mutabilidade (não confundir com eliminação!) desse fenômeno. Tanto a crítica da desigualdade como as concepções sobre justiça social - aí incluídos tanto as utopias políticas como o "igualitarismo primitivo" dos sociólogos (Müller, 2002, p. 497-498) - pressupõem, portanto, uma ordem social na qual a mutabilidade e a construção de estruturas de desigualdade possam se tornar visíveis sem que essa ordem social entre em colapso. É precisamente por isso que o estatuto da desigualdade como problema social e sociológico é uma conquista evolutiva (evolutionäre Errungenschaft) da sociedade moderna, constitutivamente vinculada ao primado da diferenciação funcional e ao princípio normativo da inclusão de todos os indivíduos nos diferentes subsistemas sociais. O primado funcional diz exatamente que a reprodução da sociedade não é idêntica à reprodução e à ontologização de uma determinada hierarquia social. Somente por conta dessa não identidade entre sociedade e estratificação social é que os sistemas funcionais, no processo de construção de suas desigualdades internas, podem tomar distância das desigualdades encontradas em seu entorno, isto é, percebê-las como contingentes e não como necessárias.

Nesse quadro teórico, a desigualdade, embora não seja identificada como o eixo primário da sociedade, tem relevância para a reprodução das operações dos distintos sistemas sociais. Em sua relação com o seguimento de seu entorno composto por indivíduos - o ser humano não é, em Luhmann, parte da sociedade, mas sim de seu entorno! -, os sistemas sociais precisam de orientações generalizáveis, que ultrapassem as particularidades de cada sistema psíquico individual. Trata-se de mecanismos de generalização de expectativas comportamentais na dimensão social, generalização essa que, sendo reiterada, funciona como critério estrutural de seleção e inclusão dos indivíduos nas operações comunicativas constitutivas dos sistemas sociais. A desigualdade refere-se, aqui, à distribuição e à atribuição desiguais dessas expectativas comportamentais, o que, na prática, significa a distribuição e atribuição desiguais de chances comunicativas. 
A diferenciação funcional implica, porém, que os subsistemas funcionais não tomam as desigualdades de seu entorno - p. ex., o sistema político não toma as desigualdades econômicas - como fatos sociais necessários; esses subsistemas são, ao contrário, como sistemas que constroem suas estruturas por meio de suas próprias operações, levados a erigir internamente suas assimetrias, mesmo que, para isso, desenvolvam interdependências com assimetrias de outra ordem. A questão aqui é que essas interdependências entre desigualdades de "dentro" e de "fora" são contingentes, ou seja, que os sistemas sociais dispõem de um grau de liberdade, ainda que sempre limitado.

Recebido para publicação e, 23 de abril de 2013 Aceito em 21 de março de 2014

\section{REFERÊNCIAS}

BARALDI, Claudio; CORSI, Giancarlo; ESPOSITO, Elena. Glossar zu Niklas Luhmanns theorie sozialer systeme. Frankfurt a. M.: Suhrkamp, 1997.

BOMMES, M., \& TACKE, V. Das Allgemeine und das Besondere des Netzwerkes. In: HOLLSTEIN, B.; STRAUSS, F. Strauss (Org.) Qualitative Netzwerkanalyse. Konzepte, Methoden, Anwendungen. Wiesbaden: VS Verlag für Sozialwissenschaften, p. 37-42, 2006.

BOURDIEU, Pierre. Die feinen Unterschiede. Frankfurt a.M.: Suhrkamp, 1982.

FRIE, Ewald.; Adel um 1800: Oben bleiben? Zeitenblicke 4 (2005), Nr. 3. Disponível em www.zeitenblicke.de/2005/3/ Frie/index_html. Acesso em 10.10.2012.

尺े HALLER, Max. Sozialstruktur und Schichtungshierarchie ‘ im Wohlfahrtsstaat. Zur Aktualität des vertikalen ڤ Paradigmas der Ungleichheitsforschung. Zeitschrift für Soziologie, n. 15, p. 167-187. 1986.

๘ KIESERLING, André. Felder und Klassen: Pierre $\vec{\circ}$ Bourdieus Theorie der modernen Gesellschaft. Zeitschrift für Soziologie, n. 37, 2008, p. 3-24.

in LUHMANN, Niklas. Gesellschaftsstruktur und Semantik. i. Studien zur Wissenssoziologie der modernen Gesellschaft, i v. 1. Frankfurt a. M.: Surhrkamp,1980.

¿ $\quad$ Symbiotische Mechanismen. In: - Soziologische Aufklärung, 3. Opladen: Westdeutscher ลे Verlag, 1981. p. 228-244.

. Soziale systeme Grundriß einer allgemeiner theorie. Frankfurt a.M.: Suhrkamp, 1984.

Ökologische kommunikation: Kann die ก็ moderne Gesellschaft sich auf ökologische Gefährdungen if einstellen? Opladen: Westdeutscher Verlag, 1986.

.Codierung und programmierung: bildung und selektion in erziehungssystem. In: : Soziologische Aufklärung 4. Opladen: Westdeutscher Verlag, 1987. p. 182-201. Die Wirtschaft der Gesellschaft. Frankfurt a. M.:
Suhrkamp, 1988.

Individuum, individualität, individualismus. In:

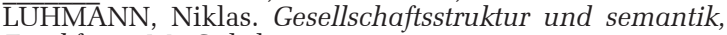
Frankfurta. M.: Suhrkamp, v. 3, p. 149-258, 1989. Verlag, 1992.

Beobachtung der moderne. Opladen: Westdeutscher

Selbstorganisation und mikrodiversität: zur Wissensoziologie des neuzeitlichen Individualismus. Soziale Systeme, n. 3, p. 23-32. 1997a.

. Die gesellschaft der gesellschaft. Frankfurt a.M.: Suhrkamp, v. 1, 2, 1997b.

Die politik der gesellschaft. Frankfurt a: M: Suhrkamp, 2002.

MÜLLER, Hans-Peter. Die drei Welten der sozialen Ungleichheit: Belohnungen, Prestige und Citzenship. Berliner Journal für Soziologie, S. 485-503. 2002

MÜNCH, Richard. Funktionale, stratifikatorische und segmentäre Differenzierung der Weltgesellschaft. KZfSS, Sonderheft 50, p. 307-310. 2010.

NASSEHI, Armin. Die theorie funktionaler Differenzierung im Horizont ihrer Kritik. Zeitschrift für soziologie, n. 33, p. 98-118. 2004a.

Inklusion, exklusion, ungleichheit: eine kleine theoretische Skizze. In: SCHWINN, Thomas (Org.). Differenzierung und Soziale Ungleichheit: die zwei Soziologien und ihre Verknüpfung, 2. Auflage. Frankfurt a. M: Humanities Online, p. 323-352, 2004b.

NEVES, Marcelo. Die staaten im zentrum und die Staaten an der Peripherie: einige probleme mit Niklas Luhmanns Auffassung von den Staaten der Weltgesellschaft. Soziale Systeme, n. 12 p. 247-273. 2006.

SCHIMANK, Uwe. Funktionale Differenzierung und soziale Ungleichheit. Die zwei Gesellschaftstheorien und ihre konflikttheoretische Verknüpfung. In: GIEGEL, H-J (Org.). Konflikt in modernen Gesellschaft. Frankfurt a. M.: Suhrkamp, 1998. p. 61-89.

et al. Das publikum der gesellschaft: inklusionsverhältnisse und Inklusionsprofile in Deutschland. Wiesbaden: VS Verlag, 2008.

SCHNEIDER, Wolfgang Ludwig. Akteure oder personen/ psychische Systeme? In: LÜDTKE, Nico; MATSUZAKI, Hironori (Org.). Akteur - Individuum - Subjekt. Fragen zu Personalität und Sozialität.Wiesdaben: VS Verlag, p. 107-115, 2011.

SCHWINN, Thomas. Soziale Ungleichheit und funktionale Differenzierung: Wiederaufnahme einer Diskussion. Zeitschrift für Soziologie, n. 27, p. 3-17. 1998.

Inklusion und soziale Ungleichheit. Berliner Journal für Soziologie, n. 10, p. 471-483. 2000.

(Org.)Differenzierung und soziale ungleichheit: die zwei Soziologien und ihre Verknüpfung, 2. Auflage. Frankfurt a. M: Humanities Online, 2004.

Verlag, 2007.

Soziale ungleichheit. Bielefeld: Transcript

STÄHELI, Urs. Die Konstruktion des Finanzpublikums: eine genealogische Analyse. In: STICHWEH, Rudolf; WINDOLF, Paul (Org.) Inklusion und exklusion: analysen zur sozialstruktur und sozialen ungleichheit. Wiesdaben: VS Verlag, p. 259-272. 2009.

Funktionale differenzierung der weltgesellschaft. KZfSS, Sonderheft 50, p. 299-306, 2010.

WEIß, Anja. Unterschiede, die einen Unterschied machen: klassenlagen in den theorie von Pierre Bourdieu und Niklas Luhmann. In: NASSEHI, Armin; NOLLMANN, Gerd (Org.). Luhmann-Bourdieu: ein Theorievergleich. Frankfurt a. M: Suhrkamp, p. 208-232, 2004. 


\section{THE PROBLEM OF SOCIAL INEQUALITY IN NIKLAS LUHMANN'S THEORY OF SOCIETY}

\author{
Roberto Dutra
}

Niklas Luhmann's Theory of Society is frequently accused of being conservative since it neglects the relevance of the structures of inequality in modern society. This article proposes an alternative reading of this theory which implies a reconsideration of the part of the structures of inequality for the reproduction of social systems. The main argument is that the structures of inequality guide the manner with which social systems select individuals for their operations. At the same time, the luhmannian thesis about the superiority of functional differentiation is defended, because while the structures of inequality may vary, assuming contingent strengths whose transformation does not represent the transformations of society, the functional differentiation represents the identity of society, remaining as an invariable and necessary dimension in the horizon of meaning in modern times.

KEYwORDS: Theory of Society. Functional differentiation. Social inequality. Contingency. Modernity.

\section{LE PROBLÈME DES INÉGALITÉS SOCIALES DANS LA THÉORIE DE LA SOCIÉTÉ NIKLAS LUHMANN}

\author{
Roberto Dutra
}

La théorie de la société de Niklas Luhmann est souvent accusée d'être conservatrice vu qu'elle ne prend pas en considération l'importance des structures d' inégalités dans la société moderne. Cet article propose une lecture alternative de cette théorie qui consiste à reconsidérer le rôle des structures d'inégalités pour la reproduction des systèmes sociaux. L'argument principal consiste en ce que les structures d'inégalités guident la manière qu'ont les systèmes sociaux de sélectionner les individus pour effectuer leurs opérations. On y défend en même temps la thèse luhmanienne concernant la primauté de la différenciation fonctionnelle puisque lorsque les structures d'inégalités peuvent varier en assumant des formes contingentes dont la transformation ne représente pas la transformation de la société, la différenciation fonctionnelle, au contraire, représente l'identité elle-même de la société et se maintient comme une dimension invariable et nécessaire aux horizons du sens de la modernité.

Mots-CLÉs: Théorie de la société. Différenciation fonctionnelle. Inégalité Sociale. Contingence. Modernité. 
